\title{
Entrevista - Vera Carnovale: A dor do outro como tema nas aulas de história Interview - Vera Carnovale:
} The Pain of Others as Subject of History Classes

Entrevista realizada por e-mail entre os dias 15 e 20 de janeiro de 2018.

Carmem Zeli de Vargas Gil ${ }^{*}$ Juliana Alves de Andrade** Juliana Pirola Balestra ${ }^{* * *}$

Vera Carnovale é pesquisadora, professora universitária e intelectual engajada. Esses e tantos outros adjetivos poderiam ser utilizados para caracterizar essa cativante portenha que generosamente nos contou sobre o seu encontro com a história, enquanto campo de atuação política e profissional. Especialista em História do tempo presente e questões sensíveis, nos últimos anos se destacou no cenário nacional e internacional ao organizar o acervo de história oral sobre o terrorismo de Estado na Argentina e por suas inúmeras publicações (livros e artigos em periódicos) sobre guerrilha, memória social e os usos públicos do passado nos diferentes espaços (escola, espaços de memória, arquivos e museus), como em Los combatientes (Carnovale, 2011), "Enseñar la historia reciente en la escuela" (Carnovale; Larramendy, 2010) e Derechos Humanos y Ciudadanía (Schujman; Clérico; Carnovale, 2005). Docente do Departamento de História da Universidad Nacional de San Martín (UNSAM), em Buenos Aires, doutora em História pela Universidad de Buenos Aires (UBA) e pesquisadora do CONICET, a instituição científica mais importante da Argentina, atualmente coordena as publicações do Centro de Documentação e Investigação da Cultura de Esquerda (CeDInCI), onde ministra seminários de pós-graduação. Entre 1998 e 2015 produziu materiais didáticos para o ensino de história recente, articulando, na prática, História e Ensino no trabalho com temas

\footnotetext{
${ }^{\star}$ Docente da Universidade Federal Rural de Pernambuco (UFRPE). Recife, PE, Brasil. julianadeandradee@hotmail.com

** Docente da Universidade Federal do Rio Grande do Sul (UFRGS). Porto Alegre, RS, Brasil. carmemz.gil@gmail.com

*** Docente da Universidade Federal da Integração Latino-Americana (Unila), Instituto Latino-Americano de Arte, Cultura e História (Ilaach). Foz do Iguaçu, PR, Brasil. juliana.balestra@unila. edu.br
} 
sensíveis, e ministrou cursos de formação de professores do Ministério da Educação da Nação e do Ministério da Educação da Cidade de Buenos Aires.

Vera Carnovale is a researcher, university professor and intellectual engaged. These and many other adjectives could be used to characterize this captivating porteña who generously told us about her encounter with History as a field of political and professional action. A specialist in present-day History and sensitive issues in recent years, she has stood out in the national and international scene by organizing the oral History collection on state terrorism in Argentina and by her numerous publications (books and periodicals) on guerrilla warfare, social memory and public uses of the past in different spaces (school, memory spaces, archives and museums), as in Los combatientes (Carnovale, 2011), "Enseñar la historia reciente en la escuela" [Teaching Recent History in School] (Carnovale; Larramendy, 2010) and Derechos Humanos y Ciudadanía [Human Rights and Citizenship] (Schujman; Clérico; Carnovale, 2005). Professor at the Department of History of the Universidad Nacional de San Martín (UNSAM), Buenos Aires, PhD in History from the Universidad de Buenos Aires (UBA) and researcher at CONICET, the most important scientific institution in Argentina, she currently coordinates the publications of the Center for Documentation and Research of the Left Culture (CeDInCI), where she teaches postgraduate seminars. Between 1998 and 2015 she produced didactic materials for the teaching of recent History, articulating, in practice, History and Teaching in the work with sensitive subjects, and ministered courses of teacher training of the Ministry of Education of the Nation and of the Ministry of Education of the City of Buenos Aires.

\section{Para empezar, cuéntenos sobre su formación escolar y cómo influenció sus elecciones académicas y profesionales.}

Antes de responder quisiera agradecer sinceramente la invitación a esta entrevista. No sé si lograré estar a la altura de las circunstancias pero, en todo caso, espero poder aportar algo, por pequeño que sea, al tema que nos convoca.

En cuanto a mi formación escolar, lo primero que me veo obligada a decir es que no tuvo influencia alguna en mis elecciones académicas y 
profesionales: no fue la escuela en sí, sino el “afuera” lo que determinó mi opción por la historia.

\section{Repaso mi escolaridad:}

Realicé la escuela primaria entre 1977 y 1983 (es decir, completamente en dictadura), en una escuela privada bilingüe, de doble turno, de esas que en la Buenos Aires de fines de los setenta representaba una opción sólo para una porción más bien pequeña de la clase media. La enseñanza del inglés y la competencia en el hockey afloran en mis recuerdos como los aspectos más destacados de la propuesta pedagógica de esa institución.

El ingreso a la escuela secundaria representó un cambio sustantivo y significativo para mí: de aquel pequeño colegio privado, de sociabilidad endogámica, ingresé a un colegio público que quintuplicaba en población (por turno) al anterior; de sociabilidad bulliciosa, abierta, variada, plebeya. Quizás haya sido este último aspecto el que haya tallado o templado cierta sensibilidad en mí, sensibilidad que en muy pocos meses se articularía con otros hilos de la trama que finalmente me llevarían a la política primero y a la historia después.

Trataré de explicarlo mejor. Es obvio e indudable que el cambio de la escuela primaria a la escuela secundaria representa un cambio sustantivo, más aún cuando ese cambio se suporpone al que implica el paso de un colegio privado a uno público. Pero en mi caso particular, esos cambios coincidieron, además, con el contexto histórico "de la transición democrática" y todas las movilizaciones que ese contexto trajo aparejado en la vida de las instituciones, de las familias, de las personas. Y es precisamente en este punto donde yo puedo identificar o reconocer el origen de mi interés por la historia.

El recuerdo es muy nítido: yo estaba terminando la escuela primaria, casi al mismo ritmo en que la dictadura se desmoronaba. En una oscura pero efervescente tarde de ese invierno de 1983, caminaba con mi padre por el centro de la ciudad [Buenos Aires]. Unas cuadras antes, frente al Congreso, nos habían repartido volantes políticos. Mi papá estaba contento. Yo tenía 12 años recién cumplidos y estaba cautivada por la campaña electoral. Caminábamos de la mano. De repente, sin mayores preámbulos, le pregunté “¿por qué se vota?”. Recuerdo perfectamente los inicios de su extensa y pausada respuesta: “todo empezó en 1930", dijo y me empezó a contar. Mi primera pregunta política recibía, así, una respuesta en clave histórica. No me acuerdo bien cómo 
siguió su relato; sí sé, en cambio, que, atenta, escuché algunos nombres por primera vez: Yrigoyen, Uriburu, Frondizi y, por supuesto, Perón. También recuerdo a "Isabelita" y a Salvador Allende. Pero lo que me resultó más revelador en aquel momento fue la dinámica que motorizaba su narrar: aquella que enfrentaba a un ellos ("los militares") con un nosotros ("el pueblo") en una pulseada que, al parecer, venía de largo rato.

Hoy, siendo ya historiadora, reconozco en la narrativa de mi padre las marcas de la Argentina transicional; y, por supuesto, que no es aquella respuesta la misma que yo ofrecería para explicar ese pasado. Pero esa noche, cuando volvimos a casa, yo estaba feliz: creía entenderlo todo. Su respuesta me había ofrecido un mapa complejo pero esclarecedor y, también, las coordenadas para saber dónde estaba bien y dónde estaba mal posicionarse en él. En resumidas cuentas, aquella tarde, la historia me había explicado la política; la historia me había ofrecido un sentido para "ordenar", "leer” y entender el presente que vivía.

Pasarían pocos meses para que yo ingresara a la escuela secundaria primero, y me internara, después, en una temprana, fugaz e intensa militancia en al Federación Juvenil Comunista (entre los 13 y los 16 años). De las clases de Historia del colegio, recuerdo poco y nada. Lamento decirlo pero es la pura verdad: la enseñanza impartida en aquel entonces en la mayoría de los colegios públicos, era aquella atiborrada de información fáctica, lineal, carente de interrogantes o problemas y, por ende, carente de sentido. De modo que no fue la instrucción allí recibida lo que me llevó a estudiar historia por aquellos años, sino mi experiencia de militancia. Fue ésta una experiencia sumamente formativa, en muchos sentidos. Por rudimentarios que puedan haber sido los resultados en aquel entonces, lo cierto es que allí aprendí a leer textos políticos, a debatir y a argumentar en política, a estudiar teoría (en realidad estudiaba una versión muy esquemática y empobrecida del marxismo pero eso no es sustantivo para lo que trato de decir aquí); y la historia estaba indefectiblemente presente en esos textos, en esos debates, en aquella teoría. De modo que diría que cuando finalmente decidí estudiar Historia, fue por algo así como una pasión por la política; y esa pasión no provino de mi formación escolar sino del "afuera": un poco de la mesa familiar y otro poco de la militancia.

El ingreso a la Universidad representó para mí un cambio para el cual no encuentro aún adjetivos. Fue algo así como cuando se corre el telón del escenario. El descubrimiento de un mundo. Diría que desde la primera clase, la pasión 
por la política quedó desplazada, sin que yo lo advirtiera siquiera, por la pasión por el saber, por la avidez de conocimiento. Nuevamente me veo obligada a contextualizar. Yo realicé el ciclo básico de ingreso en 1989 e ingresé a la Facultad en 1990. Por aquel entonces, hacía rato que había abandonado la militancia en la FJC (desencantada ya no recuerdo bien de qué), y exactamente dos años después de lo que hiciera, caían el Muro de Berlín y los socialismos reales. Hoy, suelo decir que esas caídas dejaron sin faro y sin lenguaje a millones de hombres y mujeres en el mundo entero... quizás, sin tanto dramatismo, algo de eso me haya pasado a mí en aquel momento: si el lenguaje de la política estaba cooptado por el del neoliberalismo, si la pregunta por el poder quedaba reducida a una cuestión de administración de gastos del Estado, si el fundamento inalienable de toda política ya no era la emancipación del hombre - como lo había sido para mí hasta entonces y como lo sigue siendo hasta hoy - sino el mercado o la ganancia del capital... pues entonces, nada había de convocante para mí en ese mundo. A la inversa de lo que había sucedido siete años antes, mi nueva etapa de formación - y de pasión - trascurriría, ahora, intramuros.

Los años de mi formación universitaria coincidieron con la consolidación de la llamada "profesionalización del campo"; y, aunque la historiografia resultante fuera acusada por aquel entonces de aspirar a un divorcio absoluto entre la historia y la política, debo decir, sin duda alguna, que yo me sentí - y me siento - privilegiada por los profesores que tuve. Hasta el día de hoy, recuerdo mi propio deslumbramiento en las clases teóricas de Luis A. Romero, de Enrique Tándeter, de Hilda Sábato, de Gastón Burucúa, de Oscar Terán, de José Sazbón, de Ricardo Graziano... para mí fue, realmente, una revolución copernicana. Yo venía con un know how político - y en infinita menor medida, histórico - matrizado por mi militancia (insisto, por una militancia que incluso hoy en día reivindico fundamentalmente por su valor formativo). Pero yo venía con certezas y me encontré con dudas e interrogantes; yo venía convencida de que existía La Verdad, así, con mayúsculas, y me encontré con que había interpretación, debate, problema; yo venía con esquemas explicativos unilineales, y me encontré no sólo con la multicausalidad, más importante aún, con la variedad de enfoques y abordajes. Yo no sabía que había debates dentro del marxismo, mucho menos que esos debates se disputaban la interpretación/ explicación de un fenómeno histórico; yo no sabía que había escuelas historiográficas ni que un mismo fenómeno podía ser explicado desde múltiples 
perspectivas... La noción de Historia ideludiblemente atada a la construcción de sentido, me era totalmente ajena. Para mí, el descubrimiento/aprendizaje de todo eso fue fascinante. Yo creo que fue durante esos años de estudio que me identifiqué definitivamente con una subjetividad de historiadora: una que no puede menos que buscar permanentemente la desnaturalización (de realidades, de valores, de conceptos, etc.), la comprensión, la explicación; una que se interroga por qué y cómo las cosas han llegado a ser como son y no señalar cómo deberían haber sido...

Ahora, de qué manera todo esto influenció en mis elecciones académicas y profesionales... no sabría decirlo con precisión. Mi impresión es que lo mío fue más bien un recorrido azaroso. Durante muchos años yo no tenía ninguna intención de hacer una carrera académica, de investigación (de hecho la comencé varios años después, ya pasados los 30 o casi...). Durante los últimos años de la carrera yo trabajaba como maestra en una villa miseria (algo parecido a una favela) y creía que lo mío sería por siempre el espacio educativo (ni se me cruzaba por la cabeza la posibilidad de la investigación). Pero por entonces (mediados de los noventa), surgieron en el espacio público varias intervenciones que ponían a "los años setenta" en el centro del debate público. La historiografía de aquel entonces era más bien esquiva a la historia reciente $y$, a excepción de Enrique Tandeter, ninguno de los profesores a quienes yo tenía como referentes, les entusiasmaba la idea de que yo me abocara a su estudio. Pero para mí fue como una reactivación de mi interés por la política, sólo que ahora, con otra mirada...

Lo que sigue es más bien anecdótico e, insisto, azaroso. Si los nuevos vientos traían a escena al pasado reciente, era la experiencia de la represión la que concentraba el mayor interés. A mí, en cambio, me interesaba recuperar la experiencia militante ( $\mathrm{y}$ ahora que lo escribo pienso cuánto de biográfico hubo en aquella elección). Sabía que ahí había algo interesante para "recuperar", algo que en aquel entonces yo identifiqué como "vitalidad”; más importante aún, intuía - y estoy segura que en eso no me equivoqué - que había allí algo interesante para pensar...

Yo estaba en la cátedra de América Colonial, a cargo de Enrique Tándeter y me había incorporado al Programa de Historia Oral que dirigía Dora Schwarsztein (lo cual me había abierto, a su vez, otra puerta a un universo maravilloso: el de los testimonios orales). Yo leía casi compulsivamente cuanto 
libro de los setenta se editaba por entonces, bibliografía que, dicho sea de paso, era básicamente testimonial. Con un poco con vergüenza, fui a hablar con Tándeter para insinuarle que dudaba acerca de mi interés historiográfico, que no sabía si me interesaba más el mundo indígena o el de los años setenta. Con la sabiduría y la generosidad que lo caracterizaba, me respondió simplemente: "Vera, la pasión garantiza el éxito. No te imagino estudiando nahuatl pero sí con los cachetes colorados discutiendo de política de acá para allá. Dedicate a los setenta...pero no te distraigas, concentrate y estudiá". No sé si supe o pude hacerle caso en la última parte de su consejo, pero estaré siempre agradecida por aquellas palabras que fueron las que finalmente me impulsaron a sumergirme en ese mundo fascinante de la investigación, en una clave que reunía mi pasión por la política (entendida ésta como intervención en los asuntos públicos) y mi pasión por el conocimiento histórico.

Y simplemente comencé a investigar. Ya me había decidido por la militancia revolucionaria y opté por la guerrilla porque era un tema del que todavía se sabía poco. ¿Por qué el PRT-ERP ${ }^{1}$ y no Montoneros? Supongo que sencillamente porque el lenguaje marxista me era más familiar que el vasto y heterogéneo universo del peronismo. Además mi mamá tenía un paciente que había sido del PRT-ERP, un obrero metalúrgico que vivía en la ciudad de Rosario y que estaba dispuesto a darme testimonio. Así que sencillamente, viajé $300 \mathrm{~km}$ para tocarle el timbre, grabador bajo el brazo... y así empecé. Él me fue presentando a otros y esos otros a otros.

Un año después, el Programa de Historia Oral fue convocado por la Asociación Memoria Abierta para la construcción de un Archivo Oral sobre terrorismo de Estado. Ahí trabajé 8 años... Mi recorrido hasta aquí es, en gran medida, el resultado de esos dos emprendimientos: el de mi investigación sobre el PRT-ERP y el de mi experiencia en Memoria Abierta.

\section{¿Cómo esta formación, política en primer instancia, interviene en su manera de escribir y enseñar Historia?}

Lo primero que diría es que me cuesta pensar en la formación política y en la práctica profesional como dos dimensiones claramente diferenciables... Es decir, no hay una formación o una identidad política acabada que simplemente se vuelca o gravita sobre mi escritura o sobre mi práctica docente. 
Es cierto que hay un conjunto de valores, de ideas, de voluntades políticas, etc., que en mi caso se corresponden con la tradición de izquierdas, que ineludiblemente intervienen en la delimitación de mis temas de investigación y enseñanza, en mis interrogantes, en mis enfoques, en mi estrategia de escritura, etc. Pero también lo es que la propia práctica profesional, el proceso de investigación, el de escritura, el diálogo y la discusión con pares, la interpelación de los alumnos etc., van retroalimentado, también ineludiblemente, mi formación. Definitivamente, mi visión del mundo no era la misma al comienzo de mi investigación sobre el PRT-ERP que al final del proceso de escritura de la tesis o del libro. En resumidas cuentas: mi ideología interviene en mi práctica profesional y los procesos, recorridos y resultados de esa práctica van tallando o remodelando, a su vez, mi propia formación. Esa es, por lo menos, mi impresión.

Dicho esto y volviendo a la pregunta, yo creo que el hecho de participar de una cultura de izquierdas, el hecho de haber tenido una experiencia de militancia en la izquierda, me permitió en el transcurso de mi investigación o en mi trabajo como entrevistadora en Memoria Abierta compartir con mis entrevistados y/o con mi objeto de estudio un horizonte común de sensibilidades, me permitió reconocer los guiños, identificar códigos, reflejos... Bueno, es como conocer o reconocer un lenguaje, con todo lo empático que ese reconocimiento pueda implicar. Pero a veces pienso que la tarea del historiador es similar, de algún modo, a la del traductor ( $\mathrm{y}$, ya se sabe, no se puede traducir sin traicionar). El historiador necesariamente tiene que ser capaz de ver el mundo con los ojos de su objeto de estudio pero, al mismo tiempo, debe ser capaz de ver lo que esos ojos no ven, de trascender el sistema de creencia de los propios actores, para poder explicarlo, para volverlo inteligible en otro escenario, en otro contexto. Y para ello, el movimiento empático debe complementarse con el de la extrañeza, el del distanciamiento crítico.

No sé si estoy respondiendo a la pregunta. Quizás falte decir que tanto mi práctica de escritura como de enseñanza no son en absoluto ajenas a mi irrenunciable voluntad de aportar, a través del estudio de las culturas y el pensamiento de izquierdas o de las experiencias revolucionarias, a una cultura política más atenta o más preocupada por la solidaridad, la dignidad y la emancipación humana. Es la única explicitación que se me ocurre que puedo hacer respecto de mi formación político-ideológica y mi práctica profesional: que 
estudio y enseño el pasado de las izquierdas, aún en sus fracasos y derrotas, porque creo que allí hay una promesa inclumplida de emenacipación que vale la pena repensar y recrear.

\section{Para usted, cuál es el papel de la enseñanza de la historia en el espacio escolar?}

En términos generales y muy sintéticamente podría decir que a lo largo de la historia argentina, la enseñanza de la Historia en la escuela ocupó un rol de gran importancia, estrechamente vinculado con la construcción de la ciudadanía. En los orígenes del Estado nacional, formó parte de un curriculum centrado en la educación patriótica. Esto suponía, fundamentalmente, la formación de una identidad nacional, entendida ésta como una identidad cultural, esencialista (el "ser nacional"), cuya esencia debía buscarse en los orígenes históricos de la nación. La historia escolar, junto a la geografía, la educación cívica y la enseñanza del "idioma nacional" - es decir, el castellano - debían enseñar a los niños y a los jóvenes a amar y respetar a la patria, a sus próceres, a sus símbolos (de ahí también la centralidad que tuvieron en la rutina escolar los dispositivos rituales y ceremoniosos de celebración de símbolos patrios, de efemérides, etc.). Estos propósitos respondían a la necesidad de legitimar al Estado nacional y homogeneizar política y culturalmente a un Estado de reciente construcción y convertir en argentinos a los hijos de los inmigrantes. En otras palabras, a la construcción de una ciudadanía identificada política y culturalmente con el Estado nación. Con variantes y matices, podría decirse que estos fines perduraron como criterio fundamental de la enseñanza de la historia durante casi todo el siglo XX. En términos de Hobsbawm, el papel de la historia era imponer un mito de orígenes de la nación argentina, en clave nacionalista.

Un punto de inflexión importante son los cambios curriculares que tuvieron lugar tras el fin de la última dictadura militar. Sin que se impugnara el fin de construir una identidad nacional, a partir de entonces, se reformula el propósito, postulando a la enseñanza de la historia como parte de una educación destinada al desarrollo del pensamiento crítico y reflexivo y a la construcción de un ciudadano democrático, pluralista, defensor de los derechos humanos. En esta lógica, la historia se propone como una asignatura destinada a conocer el pasado para comprender el presente y cambiar el futuro, hacía 
una sociedad más justa. Para ello, el foco de enseñanza se desplaza: de las grandes fechas patrias y las biografías gloriosas a las estructuras y procesos (económicos, sociales, políticos, culturales, etc.) protagonizados por sujetos históricos colectivos, incluyendo o "recuperando" a los anteriormente negados: clases subalternas, grupos étnicos marginados como indígenas y afro descendientes, mujeres, niños, etc. La identidad nacional se propone ahora como parte de una identidad ya no enfrentada sino más bien vinculada a la identidad regional Latinoamérica.

Ahora bien, obviamente, estas prescripciones legales/curriculares tienen un impacto muy desigual en las prácticas docentes, donde las más de las veces, conviven, híbridamente, ambos paradigmas. A lo anterior debe añadírsele, además, un propósito bastante extendido entre los docentes y que ha sido señalado recientemente y con alarma por mi colega Ariel Denkberg: el de enseñar "la verdadera historia" (enfrentada a otra "falsa", que sería una suerte de tergiversación o adulteración adrede de la verdad). Esta visión es visible en docentes que transmiten a los alumnos una visión de la historia destinada a denunciar a los "poderosos" (clases dominantes, estados centrales, etc.) y "revelar" la presencia de los dominados, de las de clases subalternas, la de los países periféricos, etc. Esta visión comparte la mirada "moralista" del paradigma "nacionalista" pero con ciertos cambios en el panteón. La resultante es una narrativa unilineal, monocausal, que anula la multiperspectividad histórica, desconoce la legitimidad de los debates historiográficos y en la que, las más de las veces, la denuncia de tenor político suplanta el análisis crítico del pasado.

Así como escribe Susan Sontag en el libro Ante el dolor de los demás, sobre las representaciones de la guerra y los efectos que ejercen sobre quién las ve; en Los combatientes usted alerta para las representaciones de las llamadas "guerras de izquierda" y los efectos que ellas ejercen en el presente, como una suerte de trauma, que hace de su abordaje en el presente un tema muy sensible. Cuando el pasado se convierte en un tema sensible para la sociedad?

Podría decirse que aunque el pasado suele ser siempre terreno de disputa, es cierto que determinados acontecimientos, fenómenos y procesos se tornan particularmente conflictivos y "sensibles" en su tramitación colectiva o social. En la actualidad, y para referirme sólo al terreno de la historia política parecieran ser especialmente aquellos vinculados a experiencias de violencias 
masivas, sistemáticas, organizadas, extremas, por definirlas rápidamente. Aunque, insisto, la vastedad de experiencias históricas de este tipo y de formas colectivas de elaboración impiden respuestas unívocas y universales.

En el caso argentino, es el pasado reciente, no en vano y bastante elocuentemente denominado, también, el "pasado que duele" o la "historia que duele", el que se constituye como tema sensible y/o alberga una pluralidad de temas sensibles. Y esto, en principio, porque la modalidad y naturaleza de la represión planificada y ejecutada por el Estado supuso un verdadero quiebre civilizatorio toda vez que transgredió los principios éticos que fundamentan la existencia y preservación de una comunidad.

A lo largo de las últimas tres décadas, el acercamiento de la sociedad a ese pasado reconoce distintos momentos que, en conjunto, dibujan un recorrido de elaboración que va del conocimiento - o, mejor dicho, re-conocimiento - de lo sucedido a la pregunta en torno a sus condiciones de posibilidad. En otras palabras, un recorrido que va del "qué pasó" al "cómo fue posible que pasara".

Ahora bien, la pregunta abre las puertas al problema de las responsabilidades colectivas y, en consecuencia, interpela jurídica, política y éticamente a una pluralidad de actores. $\mathrm{Y}$, junto a esa interpelación, se tensan las fronteras políticas e ideológicas entre lo que puede ser dicho en el espacio público y lo que no; aparecen los silencios, los temas e interrogantes que se prefiere no abordar porque son temas "delicados" o "sensibles"; en fin, temas que se resisten a ser inscriptos en una narrativa pública (a pesar de que el campo historiográficos ya ha comenzado a avanzar sobre ellos). Finalmente, parece necesario señalar que aquellas fronteras entre lo decible y lo silenciado no son estáticas sino que se van configurando por los escenarios memoriales, políticos y judiciales del presente.

Para dar algunos ejemplos de estos temas controversiales, delicados, "sensibles”... ¿Cómo incorporar en la narrativa pública la complicidad criminal de la Iglesia Católica con la represión (de una Iglesia envalentonada, además, por la elección de Berbeglio como Papa)? Si es cierto que ya no es la misma Iglesia ¿por qué no abre sus propios archivos y los pone a disposición de la justicia y de la sociedad argentina?

¿Cómo incorporar en la narrativa pública la responsabilidad que le cupo al peronismo en el poder y al propio Perón en el desencadenamiento de la masacre? ¿Qué va hacer el peronismo con esto? ¿Cómo inscribir al peronismo 
en una genealogía humanista, en una genealogía de justicia, en una genealogía que reivindique la gesta militante, cuando el propio padre fundador es uno de los grandes enunciadores de la figura de la "subversión" como aquello foráneo, ajeno al cuerpo argentino, como aquello que hay que "aniquilar", y uno de los grandes impulsores de la política represiva estatal "dentro o fuera de la ley", según sus propias palabras? ¿Cómo inscribir en la narrativa pública a los "hechos de sangre" perpetrados por las organizaciones revolucionarias armadas? ¿Qué hará la militancia revolucionaria y/o sus herederos con esos “otros muertos"? Siendo esa misma militancia hoy un componente clave del movimiento de derechos humanos ¿cómo incluirá en su relato humanista a aquellos muertos sin interpelar los fundamentos éticos y las propias prácticas que formaron parte de su historia? ¿Cómo abordar estos temas cuando en el relato que se construya sobre ese pasado se juega el sentido de la vida y de la muerte de miles de personas? ¿Cómo hacerlo sin abonar equiparaciones absurdas o relativismos de tinte negacionista?

Creo que en este punto los historiadores tenemos un desafío muy complejo, muy difícil y, al mismo tiempo, infinitamente noble.

\section{Cuando se dio cuenta que su tema de investigación era una cuestión sensible?}

Desde el minuto 1 de la primera entrevista, si no antes. Porque más allá de que yo me hubiera inclinado a estudiar a la militancia revolucionaria porque entendía que allí había una vitalidad para "recuperar" y una experiencia interesante y potente para pensar la tradición de izquierdas o la cultura política, nunca se me escapó el hecho de que se trataba de la historia de una derrota, cuando no de un fracaso; y no de uno cualquiera, sino el de una causa que había dotado de sentido a la propia existencia, a la vida y a la muerte, a la disposición de morir y de matar. Yo sabía que iba a entrevistar personas que habían perdido seres queridos, que habían sido torturadas, presas, exiliadas; que habían empuñado las armas "por un mundo mejor" y no sólo habían sido derrotadas a costa de sufrimientos inimaginables... quizás más grave aún, esa derrota se inscribía en otra mayor, me refiero a la caída del escenario de la Revolución en el mundo entero.

De modo que siempre supe que me enfrentaba a una "cuestión sensible". Lo que también sucede es que, lógicamente, en el momento de la entrevista, 
del cara a cara, todo esto se materializa de mil maneras: en los gestos, en las miradas, en los susurros, en los silencios, en las lágrimas, en los pudores, en las vergüenzas... y, también en las expectativas que la entrevista - y lo que haga el historiador con ella - generan. Testimoniar no es fácil. Y cuando hay tanto sufrimiento en la experiencia evocada se genera un vínculo muy especial, muy fuerte, diría, entre entrevistador y entrevistado. Al menos así lo viví yo, como un compromiso humano inquebrantable. Lo cual, por supuesto, me llenaba de responsabilidad, de dudas, de temores. ¡Las veces que habré soñado que yo comparecía ante un tribunal integrado por alguno de mis entrevistados! ¡Las veces que me habré desvelado de madrugada pensando qué diría tal o cual de lo que yo estaba escribiendo! ¿Se reconocerían en mis textos, en mis análisis? ¿Se debían reconocer?

Bueno, finalmente, quizás sin darme cuenta precisa, parece que opté por escribir una historia de la militancia y no una historia para la militancia. Fue la forma más honesta que pude para responder a aquel compromiso.

\section{¿Por qué estar ante el dolor de los demás nos desafía en el proceso de formación crítica?}

Yo he hecho cientos de entrevistas...cientos. Y realmente muchas veces pensé que ante el dolor de los demás sólo se puede guardar silencio... Pero lo cierto es que uno finalmente no guarda silencio... Supongo que en la medida en que el dolor del otro no nos es ajeno - al menos en mi experiencia, sobre todo en mi trabajo en Memoria Abierta - uno intenta hacer algo con ese dolor, aunque más no sea pensarlo, contárselo a otros...

Al mismo tiempo, no puedo dejar de advertir que, sobre todo en un marco educativo, la figura de la víctima genera acercamientos empáticos, identificaciones, que constituyen terrenos fértiles para dar cuenta y abordar la universalidad del ser humano... Una vez un entrevistado me dijo que los pueblos se ríen de cosas diferentes pero lloran por lo mismo. Me pareció interesante: en el humor se reconoce la particularidad, la diferencia; en el dolor nos reconocemos todos...

Ahora, me parece que el desafío es ser capaz de "hacer algo" con ese dolor; no dejarlo anclado al sufrimiento puro, no exponerlo una y otra vez morbosa y obscenamente, como muchas veces sucede con estas temáticas, sino dotarlo de sentido, restituirle su dimensión colectiva, recontextualizándolo, 
reintegrándolo a la historia en que la experiencia dolorosa tuvo lugar. Y entonces “eso que le pasó a María”, en realidad le pasó a muchos, y tiene una trama histórica que involucra a muchos más todavía. Entonces, la cuestión ya no es María y su dolor, sino la historia de esa experiencia, sus condiciones de posibilidad. La historia desestigmatiza; porque la vida de cada cual, tan única, tan singular e irrepetible, forma parte de lo que en definitiva es la historia de una experiencia colectiva.

\section{En su trabajo de capacitación docente y en la producción de secuencias y recursos didácticos, ¿cómo se abordan esos los temas sensibles?}

Bueno, en principio, se abordan, lo cual menciono porque sucede muy a menudo que la tantas veces evocada "complejidad" o "dificultad" de los temas se resuelve, sencillamente esquivandolos.

Ahora bien, debo señalar que actualmente doy clase en el espacio universitario (en carrera de grado y posgrado) y me parece que la pregunta apunta más bien a la enseñanza en la escuela primaria y secundaria. En ese terreno, y en lo relativo al pasado reciente, mi experiencia estuvo más bien centrada en tareas de capacitación docente y en la producción de secuencias y recursos didácticos para el abordaje de este tema en las aulas. De modo que, basándome en esa experiencia, responderé atendiendo a los diagnósticos, los desafíos y los fundamentos que fueron determinando mis intervenciones (en la actividad docente y en la producción de materiales educativos).

Como mencionaba anteriormente, en Argentina, tras la reapertura democrática, las decisiones en torno a políticas educativas estuvieron orientadas a promover el estudio del pasado reciente, en una clara voluntad de transmisión de valores democráticos y de respeto y promoción de los derechos humanos. Estas determinaciones, sin embargo, no estuvieron acompañadas por una estrategia efectiva que acompañara a los docentes en la determinación de qué enseñar y cómo hacerlo, a qué recursos apelar. Una de las consecuencias más evidentes de esto es la dificultad para trascender la ritualidad repetitiva de los actos conmemorativos, con los sesgos y limitaciones que ello implica. El deber de memoria que frente al horror de la última dictadura se impuso como eje de la transmisión del pasado reciente parece haber quedado anclado en la comunicación reiterativa de los crímenes perpetrados por el Estado y su condena en clave moral, al tiempo que ha postergado paralelamente el abordaje de los 
conflictos ideológicos, políticos y sociales que precedieron a la instalación del terror y signaron el período estudiado (es decir, la larga trama del contexto histórico en que aquellos crímenes tuvieron lugar). Así las cosas, pareciera que la enseñanza del pasado reciente no favorece ni la construcción del conocimiento histórico ni la construcción de una ciudadanía reflexiva, crítica.

Ante este escenario, nuestra propuesta (digo nuestra porque buena parte de mi actividad estuvo enmarcada en proyectos institucionales compartidos con otros colegas) se orientó hacia la enseñanza de una historia centrada menos en acontecimientos que en procesos; una historia donde la información fáctica ofrecida desde el recorte del docente se encuentre articulada y al servicio de categorías explicativas más generales. Una historia que, en el abordaje de los conflictos que caracterizaron al pasado reciente, atienda a la pluralidad de actores en juego, a sus respectivos intereses, intencionalidades, ideologías, prácticas políticas, etc. En resumidas cuentas, una historia atenta a la multicausalidad, a la multiperspectividad, una historia capaz de superar la mera enunciación descriptiva de los crímenes para volverse sobre el interrogante por sus condiciones de posibilidad.

Para ello, los recortes y las puertas de entrada son variados, múltiples y dependerán seguramente de las formas en que los contenidos de una temática específica se articulen con las exigencias curriculares y/o los proyectos áulicos o institucionales. En cuanto a los recursos, también los hay en cantidad y variedad (y si pudiera añadir una nota al pie diría que justamente no es la falta de recursos lo que dificulta el tratamiento del pasado reciente en el aula, sino problemas de otro tipo que van desde baches y zonas oscuras en la didáctica de las ciencias sociales hasta temores políticos y limitaciones ideológicas, entendidas éstas en sentido amplio).

Personalmente, me declaro promotora militante de la inclusión de fuentes en la enseñanza (lo cual familiariza a los alumnos con la Historia como disciplina, con el carácter interpretativo y construido del saber histórico). Y como mi experiencia ha estado centrada en el uso de testimonios puedo referirme brevemente a sus potencialidades (no en el ámbito de la investigación sino exclusivamente en el de la enseñanza).

En principio, hay un aporte muy obvio: los testimonios ofrecen un tipo de información difícilmente hallable en otras fuentes. Pero más importante aún, los relatos en primera persona suelen ofrecer un conjunto de imágenes, 
de escenas, de situaciones relativas a la experiencia cotidiana que resultan significativas para los alumnos y, en consecuencia, constituyen un "material", un "insumo" propicio para la construcción de conceptos. Dicho esto, debe advertirse que el uso de testimonios no garantiza ni per se ni automáticamente la producción de conocimiento histórico. Más aun, la fascinación y el entusiasmo que el testimonio suele generar, su uso acrítico y ritualizado ha desembocado, muchas veces, en un tipo de enseñanza que es, justamente, la que trata de superar: aquella anclada en lo anecdótico, en el apego identificatorio con las víctimas, en la banalización de los hechos dolorosos.

En una enseñanza que se propone abordar los procesos históricos en sus complejidades y conflictos facilitando en los alumnos un acercamiento reflexivo a ese pasado, los testimonios constituyen un recurso potente cuando se presentan articulados tanto con testimonios de personas con experiencias diversas, como con fuentes de época de diversa naturaleza y, también, con fuentes secundarias; es decir, con abordajes, interpretaciones y reconstrucciones que, provenientes del campo disciplinar, aporten conocimiento respecto de los contextos en que los testimonios se inscriben. Lo más rico que los testimonios ofrecen (el acceso a la experiencia y subjetividad de los sujetos) es, al mismo tiempo, su límite. De ahí la necesidad de ponerlos en diálogo con otras fuentes: para confrontarlos, para complementarlos, para interpelarlos y re-visitarlos a partir de preguntas y/o claves interpretativas que le son externas; para integrarlos en un marco explicativo que atienda a las muchas dimensiones y causalidades de la experiencia histórica.

\section{A veces un tema sensible para la historiografía no es un tema sensible para} los jóvenes en las escuelas. Para ciertas cuestiones, las interpretaciones de los historiadores y de los movimientos sociales se enfrentan con los medios y las opiniones de la familia, de los amigos, etc. ¿Quién define los temas sensibles?

La verdad es que di por sentado dos ascepciones del término (y respondí en mayor medida, en relación a una de ellas). La primera ascepción que presupuse fue aquella relativa a crímenes aberrantes como la tortura, la vejación sexual, la desaparición forzada... en fin, aquella que remite a situaciónes extremas de deshumanización, vulnerabilidad y sufrimiento. La segunda ascepción, que fue aquella a la que mayormente me referí (lo cual evidentemente constituye una marca de mis preocupaciones actuales), remite a aquellas 
temáticas controversiales, cuyo tratamiento en el espacio público se ve particularmente dificultado y/o tensado, por las implicancias políticas, éticas y memoriales que acarrean, por las hipersensibilidades o irascibilidades que, en consecuencia, despiertan. Anteriormente di algunos ejemplos cuando me referí a la complicidad de la Iglesia Católica, a la responsabilidad del peronismo, a "los otros muertos". Podría agregar, para el caso argentino, el problema de la cifra de los desaparecidos.

En cuanto a quién los define, diría que son los procesos vinculados a la memoria social; a la elaboración - siempre colectiva - del pasado; a las disputas por los sentidos otorgados a ese pasado. Esas disputas no tienen lugar en un escenario estático, sino que se despliegan en contextos históricos, políticos, judiciales (y también de sensibilidades colectivas, por qué no), específicos, que van determinando las fronteras de los relatos (y, en consecuencia, de lo que queda excluido de ellos), de lo que puede ser enunciado públicamente y lo que no, de lo que es audible y lo que no. Lo que era decible, audible, tolerable hace treinta años, puede no serlo hoy o a la inversa.

Ahora bien, dicho esto también es necesario señalar que aquella la disputa por el sentido a otorgar es, también, una disputa por la legitimidad de las voces; por la "autoridad moral" de quién puede enunciar la palabra en el espacio público y quién no. Hay voces más "autorizadas" que otras, para decirlo mal y pronto, especialmente cuando se trata de temas sensibles. Dejando a un lado el terreno judicial, podemos decir, por ejemplo, que las voces de las víctimas de crímenes aberrantes han ocupado un lugar privilegiado en los procesos de memoria, de elaboración y representación del pasado reciente. Esto es no sólo esperable y admisible sino que me animaría a decir que es deseable, que es ética y humanamente necesario: hay indudablemente una función reparadora en la palabra pública, en la inscripción del testimonio en el espacio público. Y es atendible que sean esas voces las que de alguna manera marquen el tono del qué y del cómo abordar temáticas relativas a su sufrimiento, aunque, nuevamente, esto no haya sido siempre así. Y las víctimas saben mejor que nadie que durante años nadie quería y muy pocos podían oir sobre su dolor, sobre su experiencia.

Otro tanto podría decirse de las voces de los militantes (muchos de ellos, a su vez, víctimas), principalmente en los últimos quince años: también parecen haberse erigido como voces privilegiadas - y hasta me animaría decir que 
tutelares - que han logrado imponer o consagrar un relato que indudablemente determinó las fronteras políticas de lo decible, esta vez en relación a los temas controversiales a los que me referí... En fin, creo que ya lo dije pero insisto: los historiadores tenemos aquí un desafío difícil pero noble, y finalmente ineludible.

\section{¿Cuáles son las implicaciones para el profesor al abrir la clase para tales temas? ¿Cómo orientar al profesor para que no se crie una oposición entre memoria e historia en el abordaje de temas sensibles?}

Yo pienso, en principio, que el peor escenario posible respecto de los temas controversiales del pasado es desechar su abordaje. Y lo señalo porque suele ser una opción corriente: como es un tema problemático, mejor evitemoslo. Por el contrario, yo creo que hay que arremangarse y, por difícil o desafiante que resulte, incorporarlos a la enseñanza. Ustedes en su pregunta han utilizado una palabra clave: abrir. Creo que se trata precisamente de eso: de abrir la clase a estos temas para tratarlos, para pensarlos, para debatirlos; para desnaturalizar conceptos, valores, representaciones, etc. Pero cuidado, no a partir de denuncias, sentencias o peroratas morales - que en poco y nada contribuyen a un aprendizaje significativo - sino, de nuevo, a partir de una didáctica polifónica que recupere la multiperspectiva de los sujetos históricos y de los sujetos de conocimiento (es decir, de los analistas sociales); que dé cuenta del carácter construido, interpretativo e inacabado del conocimiento histórico; y en consecuencia, que aborde la diversidad de enfoques y debates historiográficos en torno a estos temas, reconociendo explícitamente la legitimidad del disenso. Y ahora señalo esto último porque también corrientemente se configura en la práctica de enseñanza de temáticas controversiales una situación que encuentro alarmante: que el aula se convierte en espacio de adoctrinamiento.

El hecho de que el profesor tenga personalmente una posición determinada o tome clara posición respecto de un tema o problema controversial; que esa posición pueda ser eventualmente explicitada, no es equivalente a decir que es correcto o legítimo convertir al aula en tribuna doctrinaria desde la cual el profesor "baja línea" decreta verdades inapelables y dictamina cuál es una postura correcta y cuál no lo es. Si de la formación de ciudadanos críticos se trata, debe garantizarse el acceso del alumno al conjunto de las miradas 
historiográficas, al conjunto de relatos y memorias - incluyendo las que el docente repudie - y su análisis de modo que el alumno desarrolle competencias que le permitan formarse su propia opinión en base al conocimiento.

Por supuesto que esto no es fácil, es y será conflictivo, despierta y despertará incomodidades, rispideces, etc. Es inevitable y frente a esto no tengo mucho para decir. Son temas que socialmente generan o expresan hipersensibilidades, y sería absurdo pretender que el profesor o la escuela sean capaces de conjurarlas. Más bien creo que hay que incorporar al conflicto como tema, como constante, como condición ineludible de la vida social, y por ende, de la enseñanza...

En cuanto al lugar del profesor en todo esto...diría varias cosas: diría que me consta que no es tarea sencilla; que me consta que una didáctica como la que se propone le exige al profesor un conjunto de herramientas, saberes y competencias que muchas veces su formación no contempla (es imposible estar al tanto de todos los debates, de todos los enfoques, etc.); y creo que le corresponde tanto al mundo académico como a los espacios educativos institucionales acompañar, ofrecer recursos, diseñar conjuntamente estrategias, estar más a disposición... En esta misma línea, y centrándome más bien en la educación en valores, diría también que debe debatirse más institucionalmente (el profesor suele encontrarse muy solo frente a los dilemas que el tratamiento de estos temas acarrean) los criterios que establezcan posicionamientos legítimos en el aula.

Hay un artículo que, aun con mis propias reservas, suelo recomendar para debatir este problema, es el de Jaume Trilla Bernet: "Educación y valores controvertidos" (1995). Allí el autor a partir de una diferenciación entre lo que él llama valores compartidos; contravalores y valores controvertidos, establece objetivos de enseñanza y apuntala cuándo la educación debe ser "beligerantemente positiva”, cuándo "beligerantemente negativa”, cuándo debe sostener una "neutralidad positiva". Insisto: aún con mis reservas que no vienen al caso, creo que puede ser de utilidad para pensar el problema del posicionamiento docente.

Finalmente, no estoy muy segura de entender a qué se refieren cuando dicen que no se cree una oposición entre historia y memoria. Aun atendiendo a la estrechez de los vínculos entre historia y memoria (puesto que toda intervención historiográfica está determinada por un horizonte de memoria, al 
tiempo que la historia interpela a la memoria a partir de sus fundamentos epistemólógicos); yo creo que debe aproximarse a los alumnos al reconocimiento de estas dos formas de mirar el pasado, a sus vínculos, a sus especificidades...

En "Enseñar la historia reciente en la escuela: problemas y aportes para su abordaje" (2010) usted y Alina Larramendy afirman que es deseable que la enseñanza de la Historia incluya no sólo lo que ha pasado, sino también cómo los acontecimientos son relatados e interpretados por los distintos actores políticos y sociales, abriendo espacio para diferentes versiones sobre el pasado.

\section{¿Cómo incorporar en las clases narrativas controvertidas y conservadoras sin caer en la gran brecha del relativismo?}

Efectivamente, los distintos relatos y memorias sobre el pasado reciente están presentes en la escuela y, muchas veces, en boca de los estudiantes. Y esto incluye, por supuesto, versiones justificatorias del terrorismo estatal. ¿Cómo abordar, entonces, una enseñanza polifónica? ¿Todas las voces y todos los enunciados pueden circular por el espacio público del aula? ¿Deben tener legitimidad en la escuela aquellas voces reivindicativas de crímenes que la justicia nacional e internacional juzgó como de "lesa humanidad"?

Definitivamente no. El Estado argentino, a través de su sistema de justicia, probó la existencia de los crímenes de la última dictadura militar y falló en consecuencia. Ratificó, a su vez, numerosos pactos internacionales que lo comprometen ante las víctimas y sus seres queridos, ante la sociedad argentina y el mundo entero a perseguir penalmente a los responsables y a llevar adelante políticas públicas de defensa, respeto y promoción de los derechos humanos. Y la escuela tiene, entre otras cosas, la responsabilidad de transmitir y divulgar estos enunciados públicos. La ley emanada del Estado de derecho funciona como límite de lo admisible y el crimen no lo es.

Entonces, es imperioso que la polifonía de voces en torno al pasado encuentre un límite en la escuela allí donde surjan posicionamientos justificatorios o negadores del Gran Crimen. El problema es cómo se limita la polifonía, a través de qué estrategias se establece la legitimidad de algunas voces al tiempo que la inadmisibilidad de otras. Ojo, estoy dando por sentado que nos estamos refiriendo a situaciones en las que son los alumnos los portadores eventuales 
de esos discursos. En cuanto de los docentes, es sencillamente inadmisible precisamente porque es el portador, el representante en la escuela, digamos, de los enunciados públicos a transmitir.

Retomando, como decía anteriormente, yo creo que sirve poco la censura sin más de la palabra (es decir, acallar al alumno en cuestión) y/o los discursos moralistas, de denuncia... No sólo no se forman así sujetos críticos, reflexivos, sino que, más grave aún, se corre el riesgo de un aprendizaje epitelial de lo que es políticamente correcto decir y lo que no, sin ninguna apropiación significativa de los fundamentos de esos límites. Por ejemplo, es corriente hoy en la Argentina que se condene los crímenes de la dictadura pero se tolere o se acompañe con indiferencia la tortura a los presos comunes, la represión violenta de la delincuencia común o incluso se reclame la pena de muerte.

Entonces, yo creo que debe volverse sobre el acontecimiento histórico del Gran Crimen estudiando el por qué, el cómo y el cuándo se ha establecido su carácter de crimen de lesa humanidad, de crimen que ofende, que daña a la conciencia humana; de crimen que atañe a la humanidad toda y que justamente por eso es obligación de la humanidad toda, aquí y allá, perseguir penalmente a los perpetradores y solidarizarse con las víctimas; y que justamente por su carácter universal no admite "peros" en contrarios, no admite justificación política, ideológica, religiosa, moral alguna. Y allí están las normas, las leyes, los pactos, en fin, los dispositivos legales internacionales vigentes para dar cuenta de todo lo anterior. En resumidas cuentas, la enseñanza debe abordar las razones y los fundamentos por los cuales se ha establecido la indiscutible ilegitimidad de la palabra justificatoria, negadora o relativista del crimen.

Ahora bien, dicho todo lo anterior, debo admitir que mi impresión es que el problema de hacer efectiva la multiperspectividad y la polifonía en la enseñanza del pasado reciente transita hoy por otros carriles y remite más bien a los temas controversiales a los que nos venimos refiriendo. Hace poco escuché decir a una colega que desde años trabaja con la temática de la memoria en las escuelas, que era el período 1973-1976 el que presentaba más dificultades y problemas. No me sorprende. Es el período en el que se configuran las condiciones de posibilidad del terror estatal y, por ende, se interroga sobre las responsabilidades de cada quien, interpelando, paralelamente, a un conjunto variado de actores políticos y sociales (muchos de los cuales serían, a su vez, víctimas de la represión). 
La dificultad de abordar ciertas temáticas - principalmente de este período - excede a la escuela, y signa, a mi entender, el escenario actual de la memoria; y, de forma no siempre explícita y/o clara, alcanza también al campo académico. Esto hay que decirlo porque si no pareciera que el problema es sólo de la escuela y no lo es. O, mejor dicho, el problema que se presenta en la escuela forma parte de un escenario mayor.

La dificultad de abordar polifonicamente estas temáticas, atendiendo a la multicausalidad, se vincula con la alerta o el temor de que su tratamiento - o su re-conocimiento - abone, precisamente, intervenciones relativistas que pugnan por "cerrar" ese pasado, principalmente en materia de justicia. Alerta o temor absolutamente atendible puesto que, en efecto, en los últimos años, se han multiplicado en el espacio público este tipo de intervenciones.

Ahora, esas intervenciones circulan de hecho por el entramado social; y yo soy de las que creen que hay que presentar batalla no a partir del silenciamiento de los temas más difíciles en términos políticos sino, por el contrario, abordándolos; ofreciendo nuestro conocimiento, nuestro análisis, nuestras interpretaciones, nuestros fundamentos para confrontar aquellas voces. Creo, que, por difícil que resulte, hay que meterse en el barro y atravesar discusiones que muchas veces no queremos atravesar.

En la escuela, entonces, creo que hay que incluir en los contenidos de enseñanza el problema de las distintas memorias, explicitando los sujetos y contextos de enunciación de cada una de ellas. Creo también que a esas memorias hay que confrontarlas con la enseñanza de la historia. Es decir, confrontarlas tanto con los hechos como con las categorías propias de las ciencias sociales y, también con las del mundo de la política y las ideologías. Creo que los debates, allí donde se presenten deben basarse sobre juicios y no sobre pre-juicios. Confrontar las representaciones sociales (incluso las propias) con información que las fundamenten o las desmientan. Y esto es un ejercicio que muchas veces nos pone incómodos porque nos obliga a abordar temáticas que preferiríamos esquivar.

Tomemos, por ejemplo, un tema sensible que es, a su vez, caballito de batalla de las voces justificatorias: el de la actuación de las organizaciones guerrilleras que incluye, muy particularmente, el de las ejecuciones selectivas que llevaron adelante estas organizaciones. Es obvio o por lo menos muy probable que surja este tema en el aula y estoy segura de que no sirve de nada censurarlo 
(la llamada "teoría de los dos demonios" se alimentó, entre otras cosas, de representaciones sociales sobre el conflicto armado de los años 70 y esas representaciones sociales, que echan raíces en experiencias colectivas, tuvieron a aquellas acciones puntuales como referentes ineludibles).

Creo, entonces, que deben diseñarse secuencias didácticas que aborden este tema, atendiendo al contexto internacional, regional y nacional de la violencia revolucionaria, a sus sentidos, a sus objetivos, a las tradiciones religiosas, políticas e ideológicas que nutrieron esa violencia, a los actores que la protagonizaron... y también a sus prácticas, a sus acciones puntuales, incluyendo, insisto, los ajusticimientos; a las simpatías y condenas que recibió, al porqué de esas simpatías y el porqué de esas condenas; a los debates, incluso retrospectivos, que generó, entre los propios actores y dentro del campo académico (¿es realmente la existencia de la guerrilla lo que explica el advenimiento del terror estatal? ¿qué lugar le ocupo a la violencia revolucionaria en la trama que llevó al 76?).

Y por supuesto, un abordaje como el que propongo, exige incluir las razones por los cuales ninguno de aquellos hechos justifica el crimen de Estado; las razones por las cuales la violencia revolucionaria no puede ser equiparada ni política ni jurídica ni éticamente con la violencia ejercida desde el poder; las razones por las cuales los delitos cometidos por las organizaciones armadas han prescripto y los cometidos por el Estado, en cambio, son considerados de lesa humanidad y por tanto son imprescriptibles e inamnistiables.

En fin, creo, sencillamente que el análisis crítico y la enseñanza de la historia tienen mucho que aportar y los silencios muy poco...

Sé que no es fácil, insisto, y sé que estos abordajes exigen una cantera de saberes y recursos que es muy injusto reclamárselos al docente sin más. En este punto, creo que los historiadores hemos aportado mucho, pero creo que aún estamos en deuda. Y finalmente creo también, que si no expulsamos a los silenciamientos y a la autocensura de nuestras intervenciones públicas, difícilmente saldemos esa deuda, y difícilmente podamos cumplir con la razón de ser de nuestro oficio: la construcción de sentidos.

\section{¿Dicho eso, y para terminar, cómo las clases de Historia pueden contribuir a una Educación en Derechos Humanos?}

Toda narrativa histórica anida un legado implícito: su propia construcción parte de una serie de interrogantes y valores previos, determinado por un 
tiempo presente que se configura, a su vez, a partir de un horizonte de expectativas hacia el futuro. De modo que la enseñanza de la historia puede contribuir a la educación en Derechos Humanos construyendo capacidad de análisis crítico sobre los contextos de producción de las violaciones de los derechos humanos, sobre los contextos de producción de las normas nacionales e internacionales que establecen Derechos Humanos, las formas de hacerlos efectivos, como actuar ante su violación, etc. Es decir, más que imponiendo una moral determinada, aportando herramientas y saberes para la comprensión a partir de la experiencia histórica.

Como contrapartida, creo que hay una dimensión ética de la enseñanza de la historia que convierte al conocimiento adquirido en interrogantes que se vuelven sobre la propia sociedad, sobre el propio sujeto o grupo involucrados: qué valores, ideas, presupuestos o conductas de cada sujeto abonaron los escenarios pasados; cuál o cuáles de ellos son desechables de aquí en más por las implicancias que acarrean; cuál o cuáles deseables para la construcción de un futuro más atento a la dignidad de las personas.

Finalmente, diría algo muy sencillo, muy elemental: yo creo que no hay herramienta más poderosa que el saber. Por eso creo que no debe haber gesto más solidario que el compartir el saber, expandirlo... Y ya en tono casi confesional diría que sin ser una persona particularmente optimista, me habita una confianza inquebrantable en las potencialidades emancipatorias del pensamiento crítico. Y entonces creo que es en el acercamiento reflexivo, irreverente y creativo al pasado - más que en las palabras solemnes, los dogmas o los abordajes encorsetados - donde pueden delinearse nuevos horizontes, donde pueden construirse nuevas esperanzas colectivas.

\section{REFERENCIAS}

CARNOVALE, Vera. Los combatientes: historia del PRT-ERP. Siglo Veintiuno, 2011.

CARNOVALE, Vera; LARRAMENDY, Alina. Enseñar la historia reciente en la escuela: problemas y aportes para su abordaje. In: SIEDE, Isabelino (Coord.) Ciencias Sociales en la escuela: criterios y propuestas para la enseñanza. Buenos Aires: Aique, 2010. p.237-265.

SCHUJMAN, Gustavo; CLÉRICO, Laura; CARNOVALE, Vera. Derechos humanos y ciudadanía. Buenos Aires: Aique, 2005. 
TRILLA BERNET, Jaume. Educación y valores controvertidos: elementos para un planteamiento normativo sobre la neutralidad en las instituciones educativas. Revista Iberoamericana de Educación, Madrid: OEI, v.7, p.93-120, 1995.

\section{NOTA}

${ }^{1}$ Partido Revolucionario de los Trabajadores (PRT). Su brazo armado fue el Ejército Revolucionario del Pueblo (ERP).

Entrevista recebida em 10 de agosto de 2018. Aprovada em 11 de setembro de 2018. 